\title{
Does Stability Preclude Contractionary Devaluation?
}

\section{Syed Zahid Ali}

\begin{abstract}
In this paper we attempt to assess the relevance of correspondence principle in determining the possible effects of currency devaluation on balance of payments and employment. We developed a model in line with Buffie (1986) who derived a very strong result that if the model is locally stable and if labour and imported inputs are gross substitutes then devaluation will certainly improve labour employment and balance of payments at the same time. For the general production function the Buffie model predicts that devaluation cannot contract both employment and balance of payments at the same time since either of them is incompatible with the stability of the model. Buffie results by and large depend upon stability conditions of the model and what we have demonstrated that stability analysis of the model unfortunately is not free of error. In the corrected model we observe that the results derived by Buffie do not hold in general.
\end{abstract}

\section{Introduction}

Devaluation is deemed to be a major policy to rectify balance of payments problems as it restricts imports and boosts exports. For some time, however, the use of exchange rate as a policy instrument gets set back as the experience of many less developed countries are quite contrary to what was expected. In spite of mixed results, devaluation is still considered a prescription for the speedy recovery of an ill economy. For decades it remains a challenge for economists to explore reasons for mixed results as experienced by many less developed countries. Economists such as Salop (1974), Turnovsky (1981), and Lai and Chang (1989) have developed models encompassing the supply side effects of the exchange rate, to assess the main conclusion derived by Harberger (1950), Laursen and Metzler (1950), and many others that if devaluation is demand expansionary then it both increases gross-output and improves the payments balance. After incorporating the supply-side effects of the exchange rate in the model Salop has derived the result that if the monetary authority fixes the money supply then devaluation certainly reduces output and improves the payments

\footnotetext{
* The author is Associate Professor at the Lahore University of Management Sciences (LUMS), Lahore.
} 
balance at the same time. Lai and Chang on the other hand pointed out the importance of the degree of money illusion and of the nature of the tax system (progressive vs. proportional) in determining the impact effect of devaluation upon gross output. Turnovsky assesses the role of expectations regarding changes in the exchange rate and foreign prices on output. As expected Turnovsky's model predicts that devaluation will do the job so long as agents under predict the possible change in the real exchange rate.

The quest for developing a more realistic macro model led the economists to a point where no conclusive results are predicted. In the recent past Larrian and Sachs (1987), Buffie (1986), and Calvo (1983) and some others have made use of the Samuelson's (1947) correspondence principle to establish the relationship between the stability of the system and the effects of devaluations. Calvo and Larrian and Sachs have derived the result that devaluation will contract output if and only if the system is locally unstable. Buffie, on the other hand, concluded that for general technology, there exists no definite correspondence between stability and the impact effects of devaluation upon employment and balance of payments. However, in his model devaluation cannot both contract employment and reduce the payments balance. This is because either contraction in the employment or reduction in payments balance is incompatible with stability. Furthermore, if the production function is separable between primary factors and the imported input then stability guarantees that devaluation both increases employment and improves the balance of payments. Does stability preclude contractionary devaluation? The investigation of Calvo (1983), Lai and Chang (1989), Buffie (1986) and some others reveal that the correspondence between stability and the effects of devaluation very much depends upon the specification of the model. This is the same conclusion that is reached by Lizondo and Monteil (1989) in a comprehensive survey of the devaluation literature, "the relevance of the principle is inescapably model specific. A presumption of stability does not in general rule out the possibility that devaluation could be contractionary on impact”.

\section{Scope of the Study}

In this paper we attempt to improve the Buffie (1986) model to confirm his very strong result that if the model is locally stable and if labour and imported inputs are gross substitutes then devaluation will certainly improve labour employment and payments balance. In addition, Buffie has derived an interesting result by assuming the separability of the production function between primary factors and the imported input. In this special case, he found that stability guarantees that devaluation will both increase 
labour employment and improve payments balance. For general technology, however, he found that devaluation cannot both contract employment and make the balance of payments deteriorate at the same time, since this joint outcome is incompatible with the local stability of the system. Although Buffie's model is very interesting and it is one of the few studies, (along with Calvo (1983) and Larrian and Sachs (1986)) that relates the stability of the model to the impact effects of devaluation, there exist some inconsistencies in his model. Throughout the comparative static analysis Buffie assumed that the nominal wage is fixed in the short-run, while the price of the domestic good adjusts continuously to clear the goods market. These assumptions imply that the real wage must also be adjusting continuously. But, Buffie's dynamic analysis assumes that real the wage is adjusting sluggishly, over a period of time as the rate of unemployment exceeds or falls short of the natural rate of unemployment. That is, at a point in time the real wage is predetermined. The comparative static and dynamic stability sections of Buffie's analysis are inconsistent. Since Buffie has attempted to establish a correspondence between the stability conditions and the impact effects of devaluation, this internal inconsistency is central.

There is another inconsistency in the Buffie analysis. In order to derive the stability conditions, Buffie solved the two differential equations of the model simultaneously. This is the correct way of deriving the stability conditions in his model. But, a problem emerges when he justifies the sign of a particular expression by referring to the "Walrasian Stability" condition. According to this condition the equilibrium should be stable if the demand for goods is negatively sloped in the price/output plane. If, on the other hand, the demand and supply functions are both positively sloped, then equilibrium will be stable if the slope of the demand function is steeper than the slope of the supply function. In the present context, this appeal to Walrasian stability is unsatisfactory for the following reason.

In the Buffie model the dynamics of the system are explained through the wage adjustment and balance of payments equations (as we explain more fully below). Thus, the time paths of variables must be determined by involving these equations. This requires that any conditions regarding the slope of aggregate demand and the aggregate supply function of a good must derive from these dynamic equations and should not be justified making use of some other notion of stability which is not a part of the model. The equation of Walrasian stability condition cannot also be part of the model. Furthermore, the Walrasian stability condition is based on the assumption that the goods price adjusts sluggishly to restore equilibrium in 
the goods market. This, in fact, contradicts Buffie's assumption that the goods price adjusts continuously to clear the market ${ }^{1}$.

There are however, at least two ways of solving the Buffie model correctly. They both involve using the Phillips curve:

$$
\dot{\mathrm{w}}=\beta[\mathrm{u}-\overline{\mathrm{u}}]+\dot{\mathrm{p}}, \quad \beta<0
$$

where

$$
\begin{aligned}
& \mathrm{w}=\text { nominal wage rate } \\
& \mathrm{w}=\text { rate of change of no min al wage } \\
& \mathrm{p}=\text { price of the domestically produced good } \\
& \mathrm{p}=\text { time derivative of price level } \\
& \mathrm{u}=\text { actual rate of unemployment } \\
& \overline{\mathrm{u}}=\text { natural rate of unemployment } \\
& \beta=\text { speed of adjustment of nominal wage rate }
\end{aligned}
$$

but they differ according to what specification they make concerning money wages. In the first specification it is the level of the nominal wage that is fixed at each point in time. $\mathrm{p}$ can be calculated by taking the time derivative of the variables in the goods market equilibrium condition (as we explain more fully below). This assumption involves agents having perfect foresight. We can call this special case as: "Sluggish Money Wages with Perfect Foresight". An alternative is to assume that agents have static expectations; this would involve simply dropping the $\mathrm{p}$ term. We can call this special case "Sluggish Money Wages with Static Expectations".

The second method of achieving internal consistency is to assume that it is the real wage, $z=w / p$, that is predetermined at a point in time. This involves the assumption that $w$ always makes a discrete jump in response to any jump in $\mathrm{p}$, and that the real wage only adjusts through time

\footnotetext{
${ }^{1}$ See Buffie (1986) page 126.
} 
according to the following Phillips curve, which can be written by assuming $\mathrm{w}=\mathrm{p}=1$ initially as,

$$
\dot{\mathrm{z}}=\dot{\mathrm{w}}-\dot{\mathrm{p}}=\beta[\mathrm{u}-\overline{\mathrm{u}}], \quad \beta<0
$$

curve".

and we may call this special case: "A Sluggish Real Wage Phillips

Our objective in this paper is to identify Buffie's mistakes and to explain the role of stability conditions to determine the effects of devaluation on key economic variables. To stay as close as possible to the original Buffie model we report our results for the first case that is "Sluggish Money Wages with Perfect Foresight”.

After this long critical introduction we now move to the introduction of the corrected Buffie mode1.

\section{Model}

The model we will use in this paper is that of Buffie (1986) and specified as follows:

\section{Aggregate Supply}

The model assumes that the country in question is producing a single good, Q, with a general production function involving domestic labour, $\mathrm{N}$, imported input, $\mathrm{IN}$, and some fixed factor say capital, K. The supply side of the economy is explained by the following equations which are derived by making use of the Hotelling 1emma and by assuming that capital, $\mathrm{K}$, and its price, $r$, are fixed.

$$
\begin{aligned}
& \mathrm{Q}=\pi_{\mathrm{p}}(\mathrm{w}, \mathrm{p}, \mathrm{e}) \\
& \mathrm{N}=-\pi_{\mathrm{w}}(\mathrm{w}, \mathrm{p}, \mathrm{e}) \\
& \mathrm{IN}=-\pi_{\mathrm{e}}(\mathrm{w}, \mathrm{p}, \mathrm{e})
\end{aligned}
$$

The variables $\mathrm{w}, \mathrm{p}$, and e measure the wage rate, price of good, $\mathrm{Q}$, and the exchange rate respectively. Equation (1) represents the aggregate supply function and equation (2) and (3) represents the demand functions for labour and the imported input. $\pi(\mathrm{w}, \mathrm{p}, \mathrm{e})$ is the indirect variable profit function which is homogeneous of degree zero in nominal wages, w, good 
price, $\mathrm{p}$ and the nominal exchange rate, e. $\pi_{\mathrm{i}}(\mathrm{w}, \mathrm{p}, \mathrm{e})$ is the partial derivative of the indirect variable profit function with respect to the argument $\mathrm{w}, \mathrm{p}$, and e respectively.

Assuming $\mathrm{e}=\mathrm{p}=\mathrm{w}=1$ initially, the following local partial elasticities are defined.

$$
\begin{array}{lll}
\delta_{e}=-\pi_{e e} / \pi & \delta_{w}=\pi_{e w} / \pi_{e} & \delta_{p}=\pi_{e p} / \pi_{e} \\
\phi_{p}=\pi_{p p} / \pi_{p} & \phi_{e}=\pi_{p e} / \pi_{p} & \phi_{w}=\pi_{p w} / \pi_{e} \\
\varepsilon_{w}=-\pi_{w w} / \pi_{w} & \varepsilon_{e}=\pi_{w e} / \pi_{w} & \varepsilon_{p}=\pi_{w p} / \pi_{w}
\end{array}
$$

Throughout the analysis, we are assuming that all factors of production are normal. The own price elasticities are negative, and $\delta_{\mathrm{w}}$ and $\varepsilon_{\mathrm{e}}$ have the same sign. If the imported input and domestic labour are gross substitutes then $\delta_{\mathrm{w}}$ and $\varepsilon_{\mathrm{e}}$ are positive. On the other hand, if they are gross complements, then $\delta_{\mathrm{w}}$ and $\varepsilon_{\mathrm{e}}$ are negative. These assumptions imply that $\delta_{\mathrm{p}} \delta_{\mathrm{e}} \varepsilon_{\mathrm{w}} \phi_{\mathrm{p}}>0 \phi_{\mathrm{e}} \phi_{\mathrm{w}}<0 \delta_{\mathrm{w}} \phi_{\mathrm{e}}>0$

In order to make the expression used later simpler the following relationships between the local partial elasticities are used:

$$
\begin{aligned}
& \delta_{\mathrm{e}}=\delta_{\mathrm{w}}+\delta_{\mathrm{p}} \quad \varepsilon_{\mathrm{w}}=\varepsilon_{\mathrm{e}}+\varepsilon_{\mathrm{p}} \quad \phi_{\mathrm{e}}+\phi_{\mathrm{w}}=-\phi_{\mathrm{p}} \\
& \phi_{\mathrm{p}}=\theta_{\mathrm{L}} \varepsilon_{\mathrm{p}}+\theta_{\mathrm{I}} \delta_{\mathrm{p}} \quad \phi_{\mathrm{w}}=\theta_{\mathrm{I}} \delta_{\mathrm{w}}-\theta_{\mathrm{L}} \varepsilon_{\mathrm{w}} \quad \phi_{\mathrm{e}}=\theta_{\mathrm{L}} \varepsilon_{\mathrm{e}}-\theta_{\mathrm{I}} \delta_{\mathrm{e}}
\end{aligned}
$$

$\theta_{j}, j=I, L$ represent the share of the variable inputs i.e., imported input and of labour in the total cost of production respectively. Relationships in (5) are obtained by exploiting the homogeneous of degree zero property of the indirect variable profit function in $\mathrm{w}, \mathrm{p}$, e while the relationships in (6) are obtained by differentiation of the production function.

\section{Aggregate Demand}

Throughout our analysis we assume that domestic consumers purchase only one good which is domestically produced. Part of the production of this good is exported to the rest of the world. For simplicity, it is assumed that no government exists. To explicitly study the effects of devaluation which stem from the supply-side effects of the exchange rate it 
is assumed that the devaluating country imports only intermediate inputs, IN.

The market clearing condition for the home good is defined as:

$$
\mathrm{Q}=\mathrm{C}+\mathrm{X}\left(\mathrm{ep} \mathrm{p}^{\mathrm{x}} / \mathrm{p}\right)
$$

C is the total domestic consumption of $\operatorname{good} \mathrm{Q} \cdot \mathrm{p}^{\mathrm{x}}$ is the export price and $\mathrm{X}\left(\mathrm{ep}^{\mathrm{x}} / \mathrm{p}\right)$ is the total exports of the domestic good. As usual, it is assumed that exports of the domestic good depend upon relative prices, $\mathrm{ep}^{\mathrm{x}} / \mathrm{p}$. For simplicity, we assumed the export price exogenous and equal to unity. Following the monetarist approach to the balance of payments, domestic consumption is defined as the difference between the disposable income $\mathrm{Q}^{\mathrm{d}}$, and the real hoarding of money, $\mathrm{H} / \mathrm{p}$;

$$
\mathrm{C}=\mathrm{Q}^{\mathrm{d}}-\mathrm{H} / \mathrm{p}
$$

The disposable income is defined as the difference between the home good and the total payments to foreigners for intermediary inputs:

$$
Q^{d}=Q-e p^{m} I N / p
$$

$\mathrm{p}^{\mathrm{m}}$ is the foreign price of the imported inputs. For simplicity, we assumed that this price is exogenous and equal to unity.

Using the above equations the equation (8) can further be written as:

$$
\mathrm{Q}=\pi_{\mathrm{p}}(\mathrm{w}, \mathrm{p}, \mathrm{e})+(\mathrm{e} / \mathrm{p}) \pi_{\mathrm{e}}(\mathrm{w}, \mathrm{p}, \mathrm{e})-\mathrm{H} / \mathrm{p}
$$

Real hoarding is defined as a proportion of the difference between the actual real money balances. $M / p$, and their desired level, $M / p$ :

$$
\mathrm{H} / \mathrm{p}=\psi\left[\mathrm{M}^{\mathrm{d}} / \mathrm{p}-\mathrm{M} / \mathrm{p}\right], \quad \psi>0
$$

The demand for real money is defined as the linear function of value added:

$$
\mathrm{M}^{\mathrm{d}} / \mathrm{p}=\mathrm{k}\left[\pi_{\mathrm{p}}(\mathrm{w}, \mathrm{p}, \mathrm{e})+\mathrm{e} / \mathrm{p} \pi_{\mathrm{e}}(\mathrm{w}, \mathrm{p}, \mathrm{e})\right]
$$


By substituting (12) into (11) and then (11) into (10) the reader can readily derive the following reduced form of the aggregate demand function for $\operatorname{good} \mathrm{Q}$ :

$$
s Q=(1-s)(e / p) \pi_{e}(w, p, e)+\psi M / p+X(e / p)
$$

Where $\mathrm{s}=\mathrm{k} \psi$ is the short-run marginal propensity to save.

\section{Dynamics}

Besides the above seven equations (1), (2), (3), (7), (10), (11), and (12) the model also has two differential equations, which define the dynamics of the model. One equation is the accumulation identity for the balance of payments, while the second is the Phillips curve. The balance of payment identity explains the net flow of money over a period of time as:

$$
\dot{\mathrm{M}}=\mathrm{B}=\mathrm{pX}(\mathrm{e} / \mathrm{p})-\mathrm{eIN}
$$

a dot over a variable indicates the time derivative of the variable. Substituting equation (9) into (8) and then (8) into (7) gives:

$$
\mathrm{H}=\mathrm{pX}(\mathrm{e} / \mathrm{p})+\mathrm{e} \pi_{\mathrm{e}}(\mathrm{w}, \mathrm{p}, \mathrm{e})
$$

Finally, by substituting equations (12) into (11) and then (11) into (15) the following reduced form of the first differential equation of the model can easily be obtained:

$$
\dot{\mathrm{M}}=\mathrm{B}=\mathrm{p} \psi\left[\mathrm{k}\left(\pi_{\mathrm{p}}(\mathrm{w}, \mathrm{p}, \mathrm{e})+(\mathrm{e} / \mathrm{p}) \pi_{\mathrm{e}}(\mathrm{w}, \mathrm{p}, \mathrm{e})\right)-\mathrm{M} / \mathrm{p}\right]
$$

The second differential equation of the model is the equation of the Phillips curve which explains the adjustment in wages over time. As explained above we assume that the nominal wage is adjusting over a period of time according to the following Phillips curve:

$$
\dot{\mathrm{w}}=\beta\left[1+\pi_{\mathrm{w}}(\mathrm{w}, \mathrm{p}, \mathrm{e})-\overline{\mathrm{u}}\right]+\dot{\mathrm{p}}
$$

$\overline{\mathrm{u}}$ indicates the natural rate of unemployment, and $\beta$ is less than zero. For simplicity, we are assuming that the size of the labour force in the country is equal to unity. Therefore, $-\pi_{w}$, can be thought of as the fraction of the labour force demanded. The above Phillips curve explains the 
adjustment in the nominal wage through time, as it adjusts towards full equilibrium. Wages decrease (increase) when the actual rate of unemployment $1+\pi_{\mathrm{w}}(\mathrm{w}, \mathrm{p}, \mathrm{e})(=1-\mathrm{N})$ exceeds (falls short) of the natural rate of unemployment $\mathbf{u}$ or as good prices, $\mathrm{p}$, decrease (increase) over a period of time. The rate of change of the nominal wage depends not only on the parameter $\beta$ but it also depends upon the parameter which appears in the above Phillips curve when the term $\mathrm{p}$ is calculated by taking the time derivative of the variables in the goods market equilibrium condition. As explained above we may call this special case: "Sluggish Money Wages with Perfect Foresight". This completes the basic structure of the model. In the short-run there are ten endogenous variables $Q, Q^{d}, p, C, M^{d}, H, N, I N, w$, and $\mathrm{M}$ which can be given values by solving the equations (1),(2),(3),(7),(8),(9),(11),(12),(16), and (17)) simultaneously. In the long-run however, if the system is stable then $\mathrm{w}$ and $\mathrm{M}$ will converge to zero and the levels of both $\mathrm{w}$ and $\mathrm{M}$ are endogenous.

\section{Stability Analysis}

To asses the short-run and the long-run effects of devaluation on output and balance of payments position we first derive the stability condition of the model. Solving the aggregate demand (13) and supply (1) equations for the model we get:

$$
s \pi_{p}(w, p, e)=(1-s)(e / p) \pi_{e}(w, p, e)+\psi M / p+X(e / p)
$$

Assuming $\mathrm{e}=\mathrm{p}=\mathrm{w}=1, \mathrm{X}=\mathrm{IM}$, and hoarding $\mathrm{H}=0$ initially ${ }^{2}$, the total differentiation of (18) coupled with the use (4) and some manipulations gives:

$$
\mathrm{dp}=\mathrm{A}_{1} \mathrm{dw}+\mathrm{A}_{2} \mathrm{dM}
$$

where

$$
\begin{aligned}
& \mathrm{A}_{1}=\frac{-\mathrm{s} \phi_{\mathrm{w}} \theta_{\mathrm{I}}^{-1}-(1-\mathrm{s}) \delta_{\mathrm{w}}}{\Delta}, \quad \mathrm{A}_{2}=\frac{\psi}{\Delta \mathrm{X}} \\
& \Delta=\pi_{\mathrm{x}}+\mathrm{s} \theta_{\mathrm{I}}^{-1}+(1-\mathrm{s}) \delta_{\mathrm{p}}-1+\mathrm{s} \phi_{\mathrm{p}} \theta_{\mathrm{I}}^{-1}>0
\end{aligned}
$$

\footnotetext{
${ }^{2}$ We assume hoarding is zero initially then it implies that $\mathrm{M}^{\mathrm{d}} / \mathrm{p}=\mathrm{M} / \mathrm{p}=\mathrm{k}\left(\pi_{\mathrm{p}}+(\mathrm{e} / \mathrm{p}) \pi_{\mathrm{e}}\right)$ which in turn implies that $\psi \mathrm{M} / \pi_{\mathrm{e}}=\mathrm{s}\left(1-\theta_{\mathrm{I}}^{-1}\right)$
} 
From (19) we can get:

$$
\dot{\mathrm{p}}=\mathrm{A}_{1} \dot{\mathrm{w}}+\mathrm{A}_{2} \dot{\mathrm{M}}
$$

Substituting (16) into (20) and then (20) into (17) and by collecting terms we get:

$$
\dot{\mathrm{w}}=\frac{\beta\left[1+\pi_{\mathrm{w}}(\mathrm{w}, \mathrm{p}, \mathrm{e})-\overline{\mathrm{u}}\right]+\left[\mathrm{A}_{2} \psi \mathrm{p}\left[\mathrm{k} \pi_{\mathrm{p}}(\mathrm{w}, \mathrm{p}, \mathrm{e})+\mathrm{e} / \mathrm{p} \pi_{\mathrm{e}}(\mathrm{w}, \mathrm{p}, \mathrm{e})\right]-\mathrm{M} / \mathrm{p}\right.}{1-\mathrm{A}_{1}}
$$

Holding the exchange rate, e, constant, the total differentiation of (21) (coupled with the use of (4) and that at initial equilibrium $\mathrm{w}=\mathrm{p}=\mathrm{e}=1$, $\mathrm{X}=\mathrm{IM}$ and both $\mathrm{w}$ and $\mathrm{M}$ are equal to zero) yields:

$$
\begin{aligned}
& \mathrm{dw}=\frac{\beta \pi_{\mathrm{w}}\left(-\varepsilon_{\mathrm{w}} \mathrm{dw}+\varepsilon_{\mathrm{p}} \mathrm{dp}\right)+\mathrm{A}_{2} \pi_{\mathrm{p}}\left(\mathrm{s} \phi_{\mathrm{w}}-\mathrm{s} \theta_{\mathrm{I}} \delta_{\mathrm{w}}\right) \mathrm{dw}}{1-\mathrm{A}_{1}}+ \\
& \frac{\mathrm{A}_{2} \pi_{\mathrm{p}}\left(\mathrm{s} \phi_{\mathrm{p}}-\mathrm{s} \theta_{\mathrm{I}} \delta_{\mathrm{p}}+\mathrm{s} \theta_{\mathrm{I}}+\psi \mathrm{M} / \mathrm{p}\right) \mathrm{dp}-\mathrm{A}_{2} \psi \mathrm{dM}}{1-\mathrm{A}_{1}}
\end{aligned}
$$

Substituting the expression of dp from (19) back into (22) and by collecting terms we get:

$$
\mathrm{d} \mathrm{w}=\mathrm{adw}+\mathrm{bdM}
$$

where

$$
\begin{array}{cl}
\mathrm{a}=\frac{\mathrm{h}_{1}+\mathrm{A}_{2} \mathrm{~h}_{3}}{1-\mathrm{A}_{1}}, & \mathrm{~b}=\frac{\mathrm{h}_{2}+\mathrm{A}_{2} \mathrm{~h}_{4}}{1-\mathrm{A}_{1}}, \quad \mathrm{~h}_{1}=\beta \pi_{\mathrm{w}}\left[-\varepsilon_{\mathrm{w}}+\varepsilon_{\mathrm{p}} \mathrm{A}_{1}\right], \\
\mathrm{h}_{2}=\beta \pi_{\mathrm{w}} \varepsilon_{\mathrm{p}} \mathrm{A}_{2} & \mathrm{~h}_{3}=\pi_{\mathrm{p}}\left[\mathrm{z}_{1}+\mathrm{z}_{2} \mathrm{~A}_{1}\right], \\
\mathrm{h}_{4}=\pi_{\mathrm{p}}\left[\mathrm{z}_{3}+\mathrm{z}_{2} \mathrm{~A}_{2}\right], &
\end{array}
$$




$$
\begin{aligned}
& \mathrm{z}_{1}=\mathrm{s} \phi_{\mathrm{w}}-\mathrm{s} \theta_{\mathrm{I}} \delta_{\mathrm{w}} \quad \mathrm{z}_{2}=\mathrm{s} \phi_{\mathrm{p}}-\mathrm{s} \theta_{\mathrm{I}} \delta_{\mathrm{p}}+\mathrm{s} \theta_{\mathrm{I}} \delta_{\mathrm{p}}+\mathrm{s} \theta_{\mathrm{I}}+\frac{\mathrm{s} \psi \mathrm{M}}{\pi_{\mathrm{p}}} \\
& \mathrm{z}_{3}=-\frac{\psi}{\pi_{\mathrm{p}}}
\end{aligned}
$$

Similarly, holding the exchange rate, e, constant and using the assumption that at initial equilibrium $\mathrm{w}=\mathrm{p}=\mathrm{e}=1, \mathrm{X}=\mathrm{IM}$, and $\mathrm{M}=0$, the total differentiation of (17) coupled with the use of (6) above yields:

$$
\mathrm{d} \dot{\mathrm{M}}=\pi_{\mathrm{p}}\left[\left(\mathrm{s} \phi_{\mathrm{w}}-\mathrm{s} \theta_{\mathrm{I}} \delta_{\mathrm{w}}\right) \mathrm{dw}+\left(\mathrm{s} \phi_{\mathrm{p}}-\mathrm{s} \theta_{\mathrm{I}} \delta_{\mathrm{p}}+\mathrm{s} \theta_{\mathrm{I}}+\frac{\psi \mathrm{M}}{\pi_{\mathrm{p}}}\right) \mathrm{dp}-\frac{\pi_{\mathrm{p}} \psi \mathrm{dM}}{\pi_{\mathrm{p}}}\right]
$$

By substituting the equation (19) into (24) and collecting terms we get:

$$
\mathrm{d} \dot{\mathrm{M}}=\mathrm{h}_{3} \mathrm{dw}+\mathrm{h}_{4} \mathrm{dM}
$$

For convenience, we rewrite equation (23) and (25) into matrix form, we have the model in its compact form, which is useful for identifying the stability conditions:

$$
\left(\begin{array}{l}
d \dot{w} \\
d \dot{M}
\end{array}\right)=\left(\begin{array}{ll}
a & b \\
h_{3} & h_{4}
\end{array}\right)\left(\begin{array}{l}
d w \\
d M
\end{array}\right)
$$

In a system where the dynamics involve adjustment in two variables that are predetermined at each point in time, stability requires that there should exist two stable roots. In this case, stability of the system requires that the determinant and the trace of the matrix of coefficients $a, b$, $h_{3}$, and $h_{4}$ must take a positive and negative value respectively:

$$
\begin{aligned}
& \text { det }=\mathrm{ah}_{4}-\mathrm{bh}_{3}>0 \\
& \text { Trace }=\mathrm{a}+\mathrm{h}_{4}<0
\end{aligned}
$$

Substituting the values of $\mathrm{a}, \mathrm{b}, \mathrm{h}_{3}$, and $\mathrm{h}_{4}$ into (27) and (28) and after doing a series of manipulations we can show that the system will be stable if and only if: 


$$
\begin{aligned}
& \pi_{\mathrm{x}}+\delta_{\mathrm{e}}-1-\varepsilon_{\mathrm{e}} \delta_{\mathrm{w}} / \varepsilon_{\mathrm{w}}>0 \quad \text { and } \\
& \mathrm{R}=\pi_{\mathrm{x}}+\delta_{\mathrm{e}}-1+\mathrm{s} \theta_{\mathrm{I}}^{-1}-\mathrm{s} \theta_{\mathrm{I}}^{-1} \theta_{\mathrm{L}} \varepsilon_{\mathrm{e}}>0
\end{aligned}
$$

or

$$
\begin{aligned}
& \pi_{\mathrm{x}}+\delta_{\mathrm{e}}-1-\varepsilon_{\mathrm{e}} \delta_{\mathrm{w}} / \varepsilon_{\mathrm{w}}<0 \text {, and } \\
& \mathrm{R}=\pi_{\mathrm{x}}+\delta_{\mathrm{e}}-1+\mathrm{s} \theta_{\mathrm{I}}^{-1}-\mathrm{s} \theta_{\mathrm{I}}^{-1} \theta_{\mathrm{L}} \varepsilon_{\mathrm{e}}<0 \text {. and } \\
& -\beta \pi_{\mathrm{w}} \varepsilon_{\mathrm{w}}\left[\pi_{\mathrm{x}}+\delta_{\mathrm{e}}-1-\varepsilon_{\mathrm{e}} \delta_{\mathrm{w}} / \varepsilon_{\mathrm{w}}\right]-\psi\left[\pi_{\mathrm{x}}+\delta_{\mathrm{e}}-1\right]>0
\end{aligned}
$$

\section{Comparative Static Results}

Assuming that the nominal wage and the money stock are predetermined at a point in time, that both net exports and hoarding are equal to zero initially, and that $\mathrm{e}=\mathrm{p}=\mathrm{w}=1$ initially, in this section we study the effects of devaluation upon employment and the balance of payments of the country.

Treating $\mathrm{w}$ and $\mathrm{M}$ as predetermined at a point in time the total differentiation of (18) coupled with the use of (4) gives:

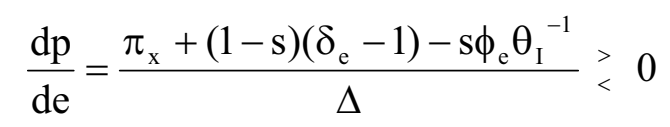

where

$$
\Delta=\pi_{\mathrm{x}}+(1-\mathrm{s})\left(\delta_{\mathrm{p}}-1\right)+\mathrm{s} \theta_{\mathrm{I}}^{-1}+\mathrm{s} \phi_{\mathrm{p}} \theta_{\mathrm{I}}^{-1} \stackrel{>}{<0}
$$




\section{Proposition 1 Devaluation may or may not necessarily improve the level of employment.}

\section{Proof:-}

Differentiating equation (2) and using the expression for $\mathrm{dp} / \mathrm{de}$ above and after some manipulation we get:

$$
\frac{\mathrm{dN} / \mathrm{N}}{\mathrm{de}}=\frac{\varepsilon_{\mathrm{w}}}{\Delta}\left[\pi_{\mathrm{x}}+\delta_{\mathrm{e}}-1-\frac{\varepsilon_{\mathrm{e}} \delta_{\mathrm{w}}}{\varepsilon_{\mathrm{w}}}+\mathrm{s}\left(1+\frac{\varepsilon_{\mathrm{e}}}{\varepsilon_{\mathrm{w}} \mathrm{v}_{\mathrm{x}}}\right)\right]
$$

where

$$
\begin{aligned}
& \Delta=\pi_{\mathrm{x}}+(1-\mathrm{s})\left(\delta_{\mathrm{p}}-1\right)+\mathrm{s} \theta_{\mathrm{I}}^{-1}+\mathrm{s} \phi_{\mathrm{p}} \theta_{\mathrm{I}}^{-1}>0 \\
& \mathrm{v}_{\mathrm{x}}=\mathrm{X} / \mathrm{Q}
\end{aligned}
$$

From (32) it is evident that due to ambiguity in the sign of the expression in the square brackets, and of $\Delta$, the employment effect of devaluation cannot be determined conclusively.

If the system is stable under condition (29), we know that $\pi_{\mathrm{x}}+\delta_{\mathrm{e}}-1>\varepsilon_{\mathrm{e}} \delta_{\mathrm{w}} / \varepsilon_{\mathrm{w}}$. However, since $\varepsilon_{\mathrm{e}}$ can take both signs and we are not sure about the sign of $\Delta$, the employment effect of devaluation cannot be determined conclusively. However, if we assume that labour and the imported input are gross substitutes $\varepsilon_{\mathrm{e}}>0$, then under condition (29) employment will increase (decrease) with devaluation if $\Delta>0(\Delta<0)$. The reader can easily confirm that for $\Delta>0$ a share of the imported input in the total cost, $\theta_{\mathrm{I}}$, increases the likelihood of employment increasing following devaluation.

If, on the other hand, the stability condition (30) is satisfied then even if in addition $\Delta$ and $\varepsilon_{\mathrm{e}}$ take a definite sign the employment effect of devaluation cannot be determined conclusively.

The above outcome contradicts the findings of Buffie. Buffie has derived the result that if labour and imported inputs are gross substitutes then devaluation necessarily increases labour employment.

Proposition 2 Devaluation may or may not necessarily improve the balance of payments. 


\section{Proof:-}

Taking $\mathrm{w}$ and $\mathrm{M}$ as predetermined at a point in time the total differentiation of (16) coupled with the use of (4) we get:

$$
\begin{aligned}
& \frac{\mathrm{dB}}{\mathrm{de}}=\frac{\overline{\mathrm{IMs}}\left(\mathrm{v}_{\mathrm{x}}^{-1}+\theta_{\mathrm{L}} \theta_{\mathrm{I}}^{-1} \varepsilon_{\mathrm{w}}\right)}{\Delta}\left[\pi_{\mathrm{x}}+\delta_{\mathrm{e}}-1-\frac{\varepsilon_{\mathrm{e}} \delta_{\mathrm{w}}}{\varepsilon_{\mathrm{w}}}\right]+ \\
& \frac{\varepsilon_{\mathrm{e}} \delta_{\mathrm{w}}}{\Delta \varepsilon_{\mathrm{w}}}\left[\frac{\left(1-\theta_{\mathrm{I}}\right) \theta_{\mathrm{L}}^{-1} \varepsilon_{\mathrm{w}}{ }^{-1}+\theta_{\mathrm{I}} \theta_{\mathrm{L}}^{-1} \varepsilon_{\mathrm{e}}^{-1}}{1+\left(1-\theta_{\mathrm{I}}\right) \theta_{\mathrm{L}}^{-1} \varepsilon_{\mathrm{w}}^{-1}}\right]>0
\end{aligned}
$$

where

$$
\Delta=\pi_{\mathrm{x}}+(1-\mathrm{s})\left(\delta_{\mathrm{p}}-1\right)+\mathrm{s} \theta_{\mathrm{I}}^{-1}+\mathrm{s} \phi_{\mathrm{p}} \theta_{\mathrm{I}}^{-1} \stackrel{>0}{<}
$$

From (33) it is evident that $\mathrm{dB} / \mathrm{de}>0$ as

$$
\begin{aligned}
& \pi_{\mathrm{x}}+\delta_{\mathrm{e}}-1>\frac{\varepsilon_{\mathrm{e}} \delta_{\mathrm{w}}\left(1-\theta_{\mathrm{I}} \theta_{\mathrm{L}}^{-1} \varepsilon_{\mathrm{w}}^{-1}\right)}{\varepsilon_{\mathrm{w}}\left(1+\left(1-\theta_{\mathrm{I}}\right) \theta_{\mathrm{L}}^{-1} \varepsilon_{\mathrm{w}}^{-1}\right.} \text { if } \Delta>0 \\
& \pi_{\mathrm{x}}+\delta_{\mathrm{e}}-1<\frac{\varepsilon_{\mathrm{e}} \delta_{\mathrm{w}}\left(1-\theta_{\mathrm{I}} \theta_{\mathrm{L}}^{-1} \varepsilon_{\mathrm{w}}{ }^{-1}\right)}{\varepsilon_{\mathrm{w}}\left(1+\left(1-\theta_{\mathrm{I}}\right) \theta_{\mathrm{L}}^{-1} \varepsilon_{\mathrm{w}}{ }^{-1}\right.} \text { if } \Delta<0
\end{aligned}
$$

If stability condition (29) along with $\Delta>0$ is satisfied then the impact effect of devaluation on payments balance is not certain. However, the reader can readily confirm that if labour and imported inputs are gross substitutes then the payments balance certainly improves upon devaluation ${ }^{3}$. But, if the stability (29) along with $\Delta<0$ is satisfied then condition (35) may or may not be satisfied. However, if we assume that $\varepsilon_{\mathrm{e}}>0$ then the stability condition (29) along with $\Delta<0$ ensures that the condition (35) must not be satisfied. The conclusion then is that in this special case,

\footnotetext{
${ }^{3}$ If labour and the imported input are gross substitutes $\varepsilon_{\mathrm{e}}>0$ then the necessary and sufficient condition under which $\mathrm{dB} / \mathrm{de}<0$ is $-\varepsilon_{\mathrm{w}} \theta_{\mathrm{I}}>\left(1-\theta_{\mathrm{I}}\right) \varepsilon_{\mathrm{e}}$. This is not possible as long as $\varepsilon_{\mathrm{e}}>0$. It is important to note if labour and the imported input are weak gross substitutes $0<\varepsilon_{\mathrm{e}}<\theta_{\mathrm{I}} \theta^{-1}$ then satisfaction of the Marshall-Lerner condition becomes sufficient for the payments balance to improve upon devaluation.
} 
devaluation must worsen the payments balance. On the other hand, if stability condition (30) is satisfied, then regardless of the sign of $\Delta$, conditions (34) and (35) may or may not be satisfied. This implies that the payments balance may or may not improve upon devaluation, even if the system is locally stable.

\section{Can devaluation both contract employment and worsen the balance of payments?}

Buffie has derived the result that if the system is locally stable then for the general production function, devaluation cannot both contract employment and worsen the payments balance. In addition, he also proved in his model that if labour and imported inputs are gross substitutes then devaluation simultaneously improves the payments balance and employment.

With the help of multipliers (32) and (33) above we can check the validity of these strong results.

\section{If Stability Condition (29) is Satisfied}

Under stability condition (29) and with $\Delta>0$ the necessary condition which makes $\mathrm{dN} / \mathrm{de}<0$ is:

$$
\varepsilon_{\mathrm{e}}<-\varepsilon_{\mathrm{w}} \mathrm{v}_{\mathrm{x}}
$$

Since both $\varepsilon_{\mathrm{w}}$ and $\mathrm{V}_{\mathrm{x}}$ are positive, from (36) it is clear that the imported input and domestic labour have to be gross complements to make $\mathrm{dN} / \mathrm{de}<0$. Similarly, under stability condition (29) and with $\Delta>0$ the necessary condition which makes $\mathrm{dB} / \mathrm{de}<0$ is to be given as:

$$
\varepsilon_{\mathrm{e}}>-\varepsilon_{\mathrm{w}} \mathrm{v}_{\mathrm{x}}
$$

From (36) and (37) it is evident that if the stability condition (29) along with $\Delta>0$ is satisfied then devaluation cannot both worsen the balance of payments and reduce employment. On the other hand, if the stability condition (29) along with $\Delta<0$ is satisfied then the reader can confirm that if labour and imported inputs are gross substitutes then devaluation both contracts employment and worsens the payments balance.

\section{If Stability Condition (30) is Satisfied}


If the system is stable under condition (30) and if $\Delta>0{ }^{4}$ then the necessary and sufficient conditions under which devaluation reduces employment and worsens the payments balance are:

$$
\begin{aligned}
& \frac{\mathrm{dN} / \mathrm{N}}{\mathrm{de}}<0 \text { if and only if } \\
& \pi_{\mathrm{x}}+\delta_{\mathrm{e}}-1<\frac{\varepsilon_{\mathrm{e}} \delta_{\mathrm{w}}}{\varepsilon_{\mathrm{w}}}\left[1-\frac{\mathrm{s} \varepsilon_{\mathrm{w}}}{\varepsilon_{\mathrm{e}} \delta_{\mathrm{w}}}-\frac{\mathrm{sv}_{\mathrm{x}}^{-1}}{\delta_{\mathrm{w}}}\right]
\end{aligned}
$$

$\mathrm{dB} / \mathrm{de}<0$ if and only if

$$
\pi_{\mathrm{x}}+\delta_{\mathrm{e}}-1<\frac{\varepsilon_{\mathrm{e}} \delta_{\mathrm{w}}}{\varepsilon_{\mathrm{w}}}\left[\frac{1-\theta_{\mathrm{I}} \theta_{\mathrm{L}} \varepsilon_{\mathrm{e}}^{-1}}{1+\left(1-\theta_{\mathrm{I}}\right) \theta_{\mathrm{L}}^{-1} \varepsilon_{\mathrm{w}}^{-1}}\right]
$$

From (38) and (39) it is evident that if the MLC is violated then the sufficient condition under which devaluation contracts employment is

$$
\frac{\varepsilon_{\mathrm{e}} \delta_{\mathrm{w}}}{\varepsilon_{\mathrm{w}}}>\mathrm{s}\left(1+\varepsilon_{\mathrm{e}} \varepsilon_{\mathrm{w}}^{-1} \mathrm{~V}_{\mathrm{x}}^{-1}\right)
$$

and the sufficient condition under which devaluation worsens the balance of payments is

$$
1-\theta_{\mathrm{I}} \theta_{\mathrm{L}}^{-1} \varepsilon_{\mathrm{e}}^{-1}>0
$$

From (40) and (41) it is evident that if labour and the imported inputs are gross complements $\varepsilon_{\mathrm{e}}<0$ and if $\varepsilon_{\mathrm{w}} \mathrm{v}_{\mathrm{x}}<-\varepsilon_{\mathrm{x}}$, then devaluation both contracts employment and worsens the payments balance.

The reader can easily confirm that if the stability condition (30) along with $\Delta>0$ is satisfied and even if the MLC is satisfied then devaluation could both contract employment and worsen the payments balance. For example, let us assume that the condition (38) is satisfied even

\footnotetext{
${ }^{4}$ It will happen if and only if $\delta_{\mathrm{w}}<\mathrm{s} \theta_{\mathrm{I}} \theta_{\mathrm{L}}^{-1} \varepsilon_{\mathrm{w}}$ and $\left|\delta_{\mathrm{w}}-\mathrm{s} \theta_{\mathrm{l}} \theta_{\mathrm{I}}^{-1}\right|>|\mathrm{R}|$.
} 
if $\varepsilon_{\mathrm{w}} \mathrm{v}_{\mathrm{x}}+\varepsilon_{\mathrm{x}}>0$. Under these circumstances the sufficient condition under which devaluation also worsens the payments balance is:

$$
\delta_{\mathrm{w}} \theta_{\mathrm{L}}^{-1} \theta_{\mathrm{I}}-\mathrm{s}\left[\varepsilon_{\mathrm{w}}+\left(1-\theta_{\mathrm{I}}\right) \theta_{\mathrm{L}}^{-1}\right]<0
$$

A careful reader could note here that if labour and imported inputs are gross complements $\left(\delta_{w}<0\right)$ then condition (42) is necessarily satisfied. This implies that if the MLC is satisfied and if $\varepsilon_{\mathrm{w}} \mathrm{v}_{\mathrm{x}}+\varepsilon_{\mathrm{e}}>0, \delta_{\mathrm{w}}<0$, and if devaluation contracts employment, then the payments balance must deteriorate at the same time.

By following the above procedure the reader can prove another interesting result. If the stability condition (30) along with $\Delta>0$ is satisfied and if labour and the imported input are gross complements then devaluation cannot both improve payments balance and increase employment. This is because either the increase in labour employment or the improvement in the balance of payments is incompatible with stability of the model.

If stability condition (30) along with $\Delta<0$ is satisfied then the necessary condition which makes $\mathrm{dN} / \mathrm{de}<0$ is:

$$
-\varepsilon_{\mathrm{w}}{ }^{-1} \mathrm{~V}_{\mathrm{x}}{ }^{-1} \varepsilon_{\mathrm{e}}<1
$$

and necessary condition which makes $\mathrm{dB} / \mathrm{de}<0$ is:

$$
-\varepsilon_{\mathrm{w}} \mathrm{v}_{\mathrm{x}} \varepsilon_{\mathrm{e}}^{-1}<1
$$

From (43) and (44) it is evident that if labour and the imported input are gross substitutes than devaluation could both contract employment and worsen the balance of payments. On the other hand, if labour and the imported input are gross complements then the condition (43) reduces to:

$$
\varepsilon_{\mathrm{e}}>-\mathrm{v}_{\mathrm{x}} \varepsilon_{\mathrm{w}}
$$

and the condition (46) reduces to:

$$
\varepsilon_{\mathrm{e}}<-\mathrm{v}_{\mathrm{x}} \varepsilon_{\mathrm{w}}
$$


From (45) and (46) it is evident that if labour and the imported input are gross complements then devaluation cannot both contract employment and worsen the payments balance.

Contrary to Buffie, the above analysis reveals that for a general specification of technology, stability of the model does not preclude the possibility that devaluation can both contract employment and worsen the payments balance.

\section{Implications of the Plausible Parameter Values and the Slope Conditions}

We can show that in an economy in which the nominal wage is predetermined at a point in time and the aggregate demand function for goods is negatively sloped, then $\Delta$ must have a positive value. On the other hand, in an economy in which the real wage is sticky at each point in time and the aggregate demand function for goods is negatively sloped, then $\mathrm{R}$ must have a positive value. It is of interest to assume that for all kinds of economies, the aggregate demand function for goods is negatively sloped in the price/output plane. We notice that if $\mathrm{R}$ has a positive value then the system will be stable under condition (29) only. Furthermore, if the system is stable under condition (29) and also if $\Delta$ has a positive value then Buffie's results hold true.

\section{Some other Limitations of the Buffie Model}

Buffie conceived a model that highlights the importance of imported inputs in the context of currency devaluation. However, surprisingly enough it is assumed throughout that labour and imported inputs are substitutes for each other. As a matter of fact at present most of the LDCs imports intermediary inputs that they cannot produce locally owing to capital constraint and technical know-how. It is too restrictive to assume that imported inputs, which are normally in the form of plants (such as sugar plants, cement plants, car assembly plants etc), machines, and oil etc, can be substituted out with labour. Whereas capital, which is deemed to be a close substitute of imported inputs was held fixed both in the short-run and the long run. In the context of currency devaluation omissions such as that imported inputs and labour cannot be substitutes for each other is important as noted by Ali (2004). Another deficiency in the Buffie model is that it does not take into account the possibility of improved efficiency, which may result in less dependency on imported inputs through time. Furthermore, the model does not include the government budget constraint that plays an important role in determining the efficacy of fiscal and monetary policies. Presently, most LDCs face a large budget deficit and 
import invariably a fixed amount of defence equipment each year. To finance the budget deficit, as already constrained by too little tax collection, these countries resorted to printing money, issuing bonds, and borrowing from international agencies and friendly countries. Government borrowing and printing money results in inflation and in this situation nominal devaluation hardly has any effect on real variables, as the real exchange rate is almost not affected.

We can improve Buffie's model by taking into account the above limitations. However, in this paper we concentrated merely on mistakes committed by Buffie to justify the sign of certain expressions appearing in the comparative static analysis. The interested reader, however, may read Ali (2004) for a model addressing most of the issues mentioned above.

\section{Currency devaluation and less developed countries}

Like the Mercantilists, LDCs are always in pursuit of promoting their exports while blocking imports at the same time. For this reason these countries embraced the Keynesian policy of currency devaluation, which is deemed to promote exports and reduce imports at the same time. Keynes himself was quite critical about the over valued currency. His anguish was deeply reflected in his work, "The Economic Consequences of $\mathrm{Mr}$. Churchill," which he wrote when Churchill decided to turn Britain to the gold standard with an overvalued pound. Keynes advises were fully backed by agencies such as the International Monetary Fund (IMF). IMF assumes that devaluation will increase competitiveness by affecting the real exchange rate. However, as time evolved economists started realising the basic weakness inherent in Keynesian policy. Keynesian theory, which is based on a strong presumption of a demand driven economy, undermines the supply side of the economy. At the same time new realities pertinent to LDCs opened up new research challenges for economists and like-minded scholars. In the last fifteen years or so the trade complexion of the world has changed dramatically. The frequency with which big multinationals have started moving from more developed countries to less developed countries increased significantly.

Contrary to their traditions most LDCs are now actively producing many import competing finished goods such as TVs, Fridges, Automobiles, etc. Presently, most of the Christmas goods sold in America are in fact manufactured in China. Silicon Valley companies engineer their software in India. The Mexican border hosts 3,500 maquiladora assembly plants from dozens of countries around the world. McDonald's sells Big Macs at 28,000 restaurants in more than 120 countries outside the USA. For this very 
reason in Doha two developing countries, India and Brazil have forged a common front to seek access to the markets of industrial countries for agricultural and manufacturing exports of developing nations. Last but not least, the accession of China and Taiwan to the WTO led economists to reevaluate the future trade pattern of the world.

For most of the LDCs the share of finished goods imports has gone down as low as ten percent of their total imports. However, to produce import competing finished goods these countries are heavily relying on the imports of intermediary goods. In the present scenario blocking imports in all forms and currency devaluation seems detrimental.

\section{Concluding Remarks}

The above investigation supports the Lizondo and Monteil (1989) finding that devaluation is not necessarily expansionary, even if the system is locally stable. It is seen that in general, there does not exist a definite correspondence between the stability of the model and the effects of devaluation on labour employment and payments balance. However, with certain additional assumptions it is observed that stability of the model managed to resolve the sign ambiguity of devaluation multipliers. It is seen that the stability conditions discussed by Buffie represent only one of two possible sets of assumptions which can generate stability. The upshot of the analysis is that Buffie's claim that if labour and imported inputs are gross substitutes, the orthodox conclusion that devaluation will be expansionary and improve the payments balance remains valid, does not hold in general. We observed a number of cases in which for the general specification of technology, devaluation simultaneously contracts employment and worsens the payments balance. This in fact contradicts Buffie's strong result that (p. 135) "If the initial equilibrium is locally stable, devaluation cannot both contract employment and worsen the payment balance." 


\section{References}

Ali, S.Z., 2004, "Currency Devaluation Under New Compelling Realities," Working Paper, Lahore University of Management Sciences.

Buffie, E.F., 1986, "Devaluation and Imported Inputs: The Large Economy Case," International Economic Review 27, 123-40

Calvo, G., 1983, "Staggered Contracts and Exchange Rate Policy," in J.A.Frenke1, ed., Exchange Rates and International Macroeconomics, Chicago: University of Chicago Press.

Harberger, A., 1950, "Currency Depreciation, Income and the Balance of Trade," Journal of International Money and Finance 4, 553-63.

Lai, C. C., and W. Chang, 1989, "Income Taxes, Supply-Side Effects, and Currency Devaluation,” Journal of Macroeconomics 11, 281-295.

Larrian, F., and J. Sachs, 1986, "Contractionary Devaluation and Dynamic Adjustment of Exports and Wages," NBER Working Paper No. 2078.

Laursen, S., and L. A., Metzler, 1950, "Flexible Exchange Rates and the Theory of Employment," Review of Economics and Statistics 32, 2242.

Lizondo, J.S., and P.J. Montie1, 1989, "Contractionary Devaluation in Developing Countries: An Analytical Overview," IMF Staff Papers $36,303-23$.

Salop, J.K., 1974, "Devaluation and Balance of Trade Under Flexible Wages," In G.Horwich and P.A. Samuelson eds., Trade, Stability, and Macroeconomics, New York: Academic Press.

Turnovsky, S.J., 1981, "The Effects of Devaluation and Foreign Price Disturbances under Rational Expectations," Journal of International Economics, 11:33-60 